\title{
Systemic silicosis associated with plasma Cell proliferation and B Iymphocyte monoclonality
}

\author{
Evgeni Gershman ${ }^{1,2,4}$, Amos Cohen ${ }^{3,4}$, Mordechai R. Kramer ${ }^{2,4}$, Avishay Elis ${ }^{1,4}$ \\ 1. Department of Internal Medicine, Rabin Medical Center Beilinson Campus, Petah Tikva, Israel. 2. Pulmonary Division, \\ Rabin Medical Center Beilinson Campus, Petah Tikva, Israel. 3. Lymphoma Service Unit, David of Hemato-Oncology \\ Center, Petah Tikva, Israel. 4. Sackler Faculty of Medicine, Tel Aviv University, Tel Aviv, Israel
}

Correspondence: Evgeni Gershman. Address: Department of Internal Medicine, Pulmonary Division, Rabin Medical Center Beilinson Campus, Petah Tikva, Israel. Email: evgenige@clalit.org.il

Received: September 6, 2015

Accepted: October 2, 2015

Online Published: October 9, 2015

DOI : $10.5430 /$ crim.v2n4p47

URL: http://dx.doi.org/10.5430/crim.v2n4p47

\section{Abstract}

Importance: Silica dust has long been known as an occupational hazard, primarily causing pulmonary fibrosis. There is a higher incidence of neoplastic diseases associated with silica exposure, mainly lung cancer.

Observation: We present a unique case of a patient with pulmonary silicosis who developed diffuse lymphadenopathy followed by features of plasma cell proliferation with B lymphocyte monoclonality.

Conclusion: We propose to add systemic lymphadenopathy, plasma cell proliferation and B lymphocytes monoclonality to the list of silicosis complications.

Relevance: In the epidemic outbreaks of silicosis, as we have seen in Israel, a malignant transformation of inflammatory reaction might be encountered more often.

\section{Keywords}

Silicosis, Systemic inflammation, Plasma cell proliferation, B lymphocyte monoclonality

\section{I ntroduction}

Silica dust has long been known as an occupational hazard, primarily causing pulmonary fibrosis as a result of acute or chronic exposure and inhalation of free silica particles or silica containing dust ${ }^{[1]}$. The toxicity of crystalline silica appears to result from their ability to interact with aqua's media to generate free radicals and to injure pulmonary cells, like alveolar macrophages. These cells, in turn, produce cytokines that cause inflammation and fibrosis ${ }^{[2]}$.

Silicosis is a disease of vary clinical presentation. Affected individuals might be asymptomatic with only an abnormal chest radiograph, whereas chronic cough and dyspnea on exertion are common among symptomatic patients ${ }^{[3]}$. Advanced states are represented by weight loss, fatigue, as well as pleuritic pain ${ }^{[4]}$.

Recently, we have observed a silicosis epidemic in Israel due to introduction of artificial stone with $94 \%$ content of silica. It resulted in 200 new cases of silicosis of whom 18 needed lung transplantation ${ }^{[5]}$. 
The association between silica exposure and autoimmune diseases was already described in the beginning of 20th century when stone masons presented with high incidence of scleroderma. Since then numerous case reports and series have showed an association between silica exposure and systemic sclerosis, systemic lupus erythematosus, ANCA vasculitis and rheumatoid arthritis suggesting that silicosis is a systemic inflammatory disease ${ }^{[6]}$.

Studies of silica exposure and the incidence of lung cancer have shown that after excluding smoking there is still a positive correlation between the two ${ }^{[7]}$. Furthermore, the International Agency for Research on Cancer determined crystalline silica as a cause of lung cancer ${ }^{[8]}$.

We present a unique case of a patient with pulmonary silicosis who developed diffuse lymphadenopathy followed by plasma cell proliferation with B cell monoclonality as an unusual silicosis associated systemic inflammatory reaction.

\section{Case presentation}

A 53-year-old male was admitted because of a gradual respiratory and functional decline. He has been working in an artificial stone factory using silica for the last 30 years, without history of tobacco use.

Several years ago, due to dyspnea, mediastinal lymphadenopathy and massive interstitial infiltrate a trans bronchial biopsy revealed pulmonary silica nodules and the diagnosis of silicosis was made. During the last year a gradual respiratory and functional decline was developed, followed by substantial diffuse lymphadenopathy in the mediastinum, neck, axillae, retroperitoneum and inguinal region, accompanied by hepatomegaly.

On presentation he complained about fever up to $38.5^{\circ} \mathrm{C}$ for the last several weeks along with purulent sputum and weight loss of $12 \mathrm{~kg}$ in two months. Physical examination revealed $\mathrm{O}_{2}$ saturation on room air of $94 \%$, pallor of the skin and mucosa, breath sounds were normal with no heart murmurs, generalized lymphadenopathy was noted without hepato-splenomegaly. Laboratory analysis revealed microcytic anemia $(\mathrm{Hb}=9.8 \mathrm{gr} \%$; $\mathrm{MCV}=72.4 \mathrm{fl})$, thrombocytosis (447 K/micl), normal white blood cell count, as well as significant hypo-albuminemia of 2.3 gr\%, hyper-globulinemia of 7.4 gr\%, LDH = $518 \mathrm{U} / \mathrm{L}, \mathrm{CRP}=17.1 \mathrm{mg} \%$ (upper limit 0.5) with normal electrolyte level and liver and kidney function tests.

A chest CT scan showed progression of the pulmonary consolidations seen before and mediastinal lymphadenopathy (see Figure 1).

A biopsy of an axillary lymph node revealed a reactive proliferative state.

Serum protein electrophoresis showed a high spike of gamma globulins with positive cryoglobulins of mixed nature IgM/IgG in a titer of 1:8. Immuno-fixation revealed an M-spike of IgM. ANA was positive in a titer of 1:160 with normal range anti DNA and rheumatoid factor.

Bone marrow biopsy displayed myeloid, erythroid and megacaryocytes linage of maturation in normal range. There were 20\% plasma cell CD138 positive, mostly para-vascular in a few rows and mature groups, with equal number of kappa and lambda positive cells, equal stain for IgG and IgA, few IgM and less than 10\% IgG4 positive cells, negative for IgD, CD20, CYCLIN D1, CD56 and C-KIT stains. The marked plasma cell proliferation contained intra-cytolplasmic inclusion bodies assumed to be globulin crystals (see Figure 2). Though plasma cell proliferation was present, the final results were non-diagnostic for monoclonal process.

Shortly afterwards, another biopsy of newly enlarged cervical lymph node presented plasma cell infiltrates constituting 95\% of cellular matter with evidence of small follicular remnants stained CD23 CD20 positive. All plasma cells were mature small to medium size with pronounced mitotic activity. CISH stain showed a kappa to lambda 7:1 ratio. IgH PCR 
analysis revealed B cell monoclonality on polyclonal background with a high suspicion index of malignant transformation (see Figure 3).
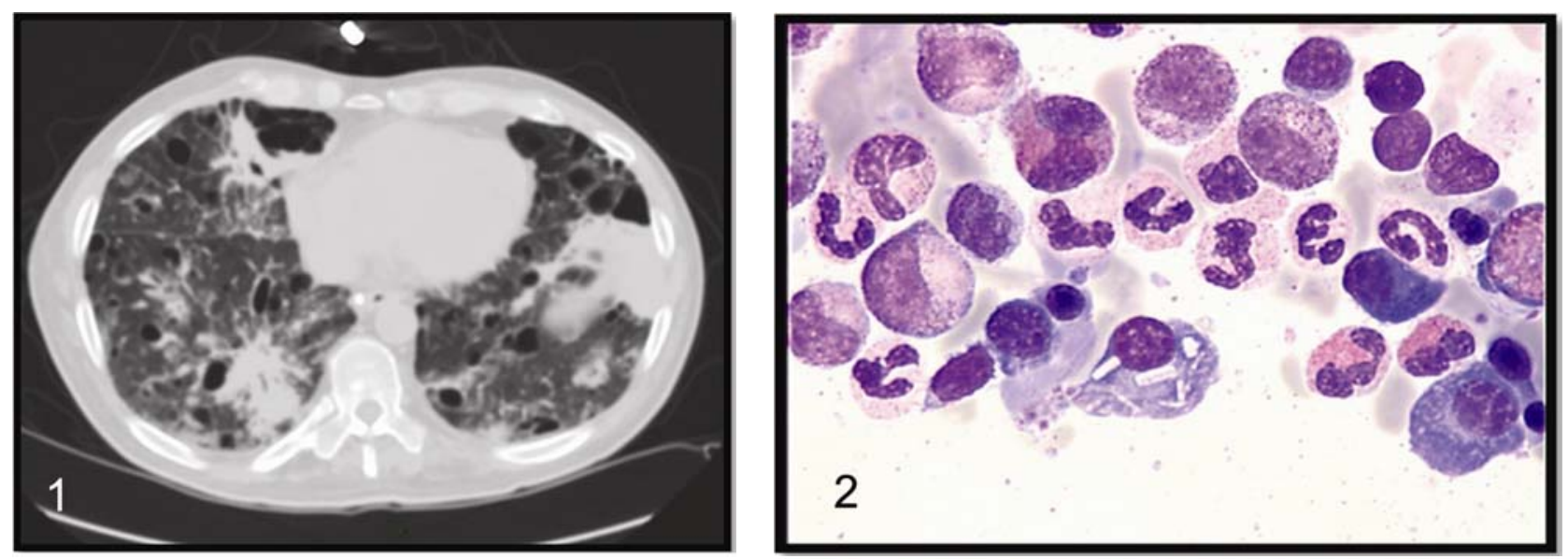

Figure 1. High resolution CT showing massive parenchymal consolidations

Figure 2. Bone marrow biopsy showing plasma cell intracytoplasmic crystals (Giemsa stain $\times 20$ )

Figure 3. Lymph node biopsy showing B cell monoclonality on polyclonal background (H\&E stain $\times 40)$

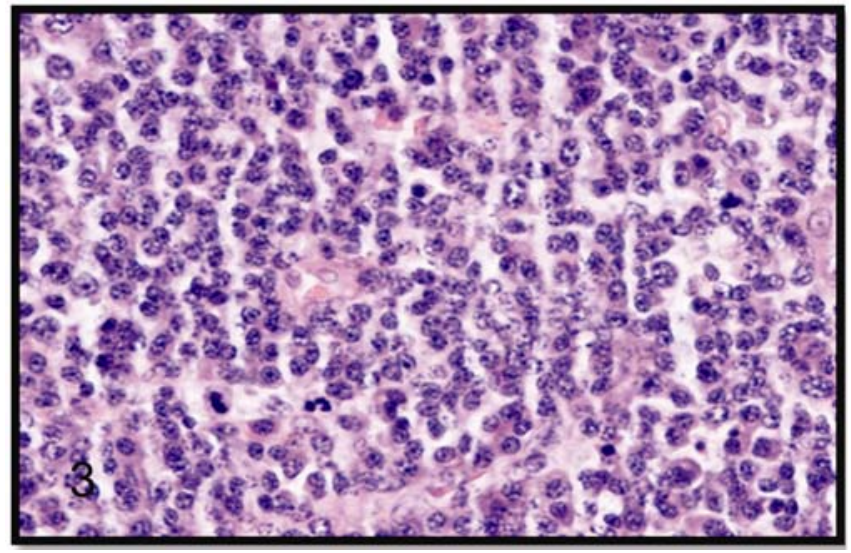

A therapeutic trial of systemic glucocorticoids aimed to suppress the massive inflammatory reaction made no clinical change and the patient succumbed to multi organ failure and died 5 months after first presentation.

\section{Discussion}

We presented a unique case of silicosis inducing plasma cell proliferation containing intra-cellular crystals and B lymphocyte monoclonality.

To our knowledge there are no previously published reports of silicosis progression to lymphoproliferative disease, except a case of a 70-year-old man with a history of pulmonary silicosis and a sub-carinal mass which was found to be Hodgkin's disease $^{[9]}$.

One of the unique features of the plasma cell proliferation in our case were the intra-cytoplasmic inclusion bodies. Intra cellular crystal is known to appear in a vast array of diseases including pneumoconiosis and silicosis in specific ${ }^{[10]}$. On the other hand, crystals in plasma cells is a rare phenomenon that was observed, mainly as part of plasma cell dyscrasia, helicobacter pylori gastritis, rheumatologic disorders and granulocyte sarcoma ${ }^{[11,12]}$.

Previous report of bone marrow involvement in silicosis revealed inconspicuous accumulations of silica-containing macrophages, free silica, slight lymphocyte and plasma cell infiltration, as well as reticulin fiber formation ${ }^{[13]}$. Our case had some similarity with this description. The crystals inside the plasma cells in our cases were assumed to be 
immunoglobulin crystallization as seen in plasma cell dyscrasias. The appearance of such crystals with monoclonal IgM gammopathy along with the clinical presentation might be an example of hematologic malignancy complication of silicosis.

As previously showed, silica exposure and silicosis may inflict rheumatologic and auto immune disease in humans. Furthermore, silica has shown in animal models to produce direct activation of the immune system and as such can be addressed as a systemic disease of inflammatory nature ${ }^{[2,15]}$. In the case presented here, the patient presented with an inflammatory nature disease, clinically evident by fever, weight loss and diffuse multi regional lymphadenopahty, followed by inflammatory markers, like hyperglobulinemia and high level of CRP, that kept rising with the progression of the silicosis. Eventually, the patient's lymphatic system converted, from a systemic inflammatory reaction, to a quasi-malignant lympho-proliferative/plasma cell neoplasia. Such hematologic changes from proliferation to malignancy are well known in cases of Celiac disease and Helicobacter pylori infection ${ }^{[14,15]}$.

This is the first report of systemic lymphadenopathy induction of plasma cell proliferation and B lymphocytes monoclonality. We presume that in the future we will encounter more such cases and considering lymphoproliferative disorders as a complication of silicosis might be in place.

\section{References}

[1] Ashima M. Prevalence of Connective Tissue Disease in silicosis - (1985-2006) - A report from the State of Michigan Surveillance System for Silicosis. AMER. J. of Industrial Medicine. 2011; 54: 255-262. PMid:20957678 http://dx.doi.org/10.1002/ajim.20917

[2] Hauax F. New developments in the understanding of immunology in silicosis. Curr Opin Allergy Clin Immunol. 2007; 7(2): $168-73$.

[3] Xipell JM, Ham KN, Price CG, et al. Acute silicoproteinosis. Thorax. 1977; 32: 104. PMid:17351471 http://dx.doi.org/10.1097/ACI.0b013e32802bf8a5

[4] Wang XR, Christiani DC. Respiratory symptoms and functional status in workers exposed to silica, asbestos, and coal mine dusts. J Occup Environ Med. 2000; 42: 1076. PMid:190727 http://dx.doi.org/10.1136/thx.32.1.104

[5] Kramer MR. Artificial stone silicosis: disease resurgence among artificial stone workers. Chest. 2012; 142(2): 419-24. http://dx.doi.org/10.1097/00043764-200011000-00009

[6] Koeger AC. Silica Associated Conecctive Tissue Disease. Medicine. 1995; 74(5). PMid:22383661 http://dx.doi.org/10.1378/chest.11-1321

[7] Cassidy A, 't Mannetje A, van Tongeren M, et al. Occupational exposure to crystalline silica and risk of lung cancer: a multicenter case-control study in Europe. Epidemiology. 2007; 18: 36. PMid:7565064 http://dx.doi.org/10.1097/00005792-199509000-00001

[8] International agency for research on cancer. IARC monographs on the evaluation of carcinogenic risks to humans: Silica, some silicates, coal dust, and para-aramid fibrils. World Health Organization; International Agency for Research on Cancer, 337, Geneva, Switzerland. 1997. PMid:17149143 http://dx.doi.org/10.1097/01.ede.0000248515.28903.3c

[9] Brinchault G. Bronchial erosion of mediastinal lymphadenopathy associates with Hodgkin's disease. Rev Mal Respir. 2004; 21(1): $137-40$.

[10] Dogan S, et al. Crystal storing histiocytosis: Report of a case, Review of the literature and proposed classification. Head and Neck Pathology. 2012; 6: 111-120. http://dx.doi.org/10.1016/S0761-8425(04)71245-0

[11] Stewart CJ, Spagnolo DV. Crystalline plasma cell inclusions in helicobacter-associated gastritis. J Clin Pathol. 2006; 59: 851-854. PMid:22430767 http://dx.doi.org/10.1007/s12105-011-0326-3

[12] Strauchen JA, Gordon RE. Crystalline inclusions in granulocytic sarcoma. Arch Pathol Lab Med. 2002; 126: 85-86. PMid:16537672 http://dx.doi.org/10.1136/jcp.2005.033233

[13] Eide J, Gylseth B, Skaug V. Silicotic lesions of the bone marrow: histopathology and microanalysis. Histopathology. 1984; 8(4): 693-703. PMid:11800655

[14] Fischbach W. Gastric MALT lymphoma-update on diagnosis and treatment. Best Pract Res Clin Gastroenterol. 2014; 28(6): 1069-77. PMid:6479909 http://dx.doi.org/10.1111/j.1365-2559.1984.tb02381.x

[15] Kelly CP, Bai JC, Liu E, et al. Advances in diagnosis and management of celiac disease. Gastroenterology. 2015; 148(6): 1175-86. PMid:25439072 http://dx.doi.org/10.1016/j.bpg.2014.09.006 